\title{
REFLECTION
}

\section{The Critical Role of Clerks in the Patient-Centered Medical Home}

\author{
Samantha L. Solimeo, PbD, MPH $H^{1,2}$ \\ Greg L. Stewart, $P b D^{1,3}$ \\ Gary E. Rosenthal, $M D^{1,2}$ \\ 'VISN 23 Patient Aligned Care Team \\ Demonstration Lab, and Center for Com- \\ prehensive Access \& Delivery Research and \\ Evaluation (CADRE), Iowa City VA Health \\ Care System, Iowa City, Iowa \\ ${ }^{2}$ Division of General Internal Medicine, \\ Department of Internal Medicine, Carver \\ College of Medicine, University of Iowa, \\ Iowa City, lowa \\ ${ }^{3}$ Tippie College of Business, University of \\ Iowa, lowa City, lowa
}

Conflicts of interest: authors report none.

\section{CORRESPONDING AUTHOR}

Samantha L. Solimeo, PhD, MPH

Department of Veterans Affairs

CADRE (152)

Iowa City VA HCS

601 Highway 6 West

Iowa City, IA 52246

samantha.solimeo@va.gov

\begin{abstract}
Research evaluating the effectiveness, function, and implementation of patientcentered medical homes (PCMHs) has found major socioprofessional transformations and contributions of primary care physicians and, to a lesser degree, nurses. Our longitudinal ethnographic research with teams implementing PCMH in Veterans Health Administration (VHA) primary care identifies the important but largely underutilized contributions of clerks to PCMH outcomes. Although the relationship of high-performing clerical staff to patient satisfaction is widely acknowledged, PCMH can be further enhanced by enabling clerks to use administrative tasks as conduits for investing in long-term personalized relationships with patients that foster trust in the PCMH and the broader health care organization. Such relationships are engendered through the care-coordination activities clerks perform, which may be bolstered by organizational investment in clerks as skilled health care team members.
\end{abstract}

Ann Fam Med 2016;14:377-379. doi: 10.1370/afm.1934.

\section{INTRODUCTION}

he patient-centered medical home (PCMH) has emerged as a promising strategy for revitalizing primary care. The model seeks to improve chronic disease management, care coordination across clinicians and delivery systems, and patient access. At the heart of the model is the structuring of health care delivery around interdisciplinary teams that promote interprofessional competence and in which team members strive to practice at the top of their professional license or competence. ${ }^{1}$

Initial studies suggest that the PCMH model may improve quality of care, lower health care costs through decreases in hospital admissions and emergency department visits, and increase clinician and patient satisfaction. ${ }^{2,3}$ In tandem, evaluations of the PCMH have highlighted the transformation of roles and associated $\mathrm{PCMH}$-specific educational needs of clinically trained staff, such as primary care physicians and nurses. ${ }^{1,4,5}$ In contrast, attention to the role and training of the nonclinically trained team member-primary care clerks-has been exceptionally scant outside their inclusion in measures of patient satisfaction with telephone and scheduling practices. Social scientists have documented primary care front office staff efforts to reduce patient emotional distress and to advocate for service on patients' behalf in traditional primary care settings, ${ }^{6-8}$ but to our knowledge there has been no substantive attention paid to the nature and importance of clerks' role under the team-based PCMH model.

\section{CLERKS IN THE VETERANS HEALTH ADMINISTRATION EXPERIENCE}

Beginning in 2010, the Veterans Health Administration (VHA) capitalized on long-standing investments in electronic health records, an integrated pharmacy, telehealth, and chronic disease management by 
nationally implementing $\mathrm{PCMH}$ in all primary care settings. Known as PACT, or the Patient Aligned Care Team, ${ }^{1,2}$ the PCMH adopts 4 -person teams that include a primary care clinician, who is a physician, physician assistant, or nurse practitioner; a registered nurse, who provides care management functions; a clinical associate (typically a licensed practical nurse); and an administrative associate, informally referred to as a clerk. VHA clerks perform administrative duties similar to those of front office staff in private sector settings, eg, greet patients, verify patients' demographic and payer information in the electronic health record, answer and route incoming queries and telephone calls, place appointment reminder calls, and manage reception area climate. Yet these clerks differ from traditional front office staff in that they are considered fully engaged members of a health care team, with commensurate expectations that they develop ownership of a patient panel and participate in quality improvement.

Our long-term ethnographic research in the VHA setting indicates that clerks' contributions, often unrecognized, have important implications for care coordination, access, delivery of patient-centered care, and the ethical nature of primary care..$^{19-12}$ By observing PACTs in the clinic and at training events, and by interviewing staff one-on-one, we developed an understanding of how clerks contribute to care. ${ }^{1,9,10,13}$ These observations have provided a basis for our developing and sharing the following key insights and suggestions related to the potential for clerks to improve care quality.

Within PACTs, clerks provide administrative and operational support for the delivery of comprehensive primary care services that are consistent with patients' goals of care. More importantly, however, clerks are also "friendly faces" who initiate and maintain relationships with patients and their families and between patients and the other PACT team members. Clerks' demeanor and ability to project familiarity with individual preferences engender patient trust and satisfaction. Patients who are dissatisfied with appointment availability or other aspects of their care often express frustration to clerks, whose ability to respond in a conciliatory tone helps restore patient satisfaction with the care team. Patients confide in clerks by sharing personal details, such as caregiving roles, recent family deaths, or upcoming retirement plans. Effectively managing such sociomedical information through interpersonal interactions is critically important in large health care settings, where clerks typically have a limited range of administrative tasks but-by being the voice on the telephone recognized by patients-possess great potential to surmount the impersonal nature of a large, complex organization.
As a health care team member, clerks learn and adapt to clinical staff preferences and practices. In so doing, clerks offer customized institutional knowledge that constitutes valuable technical contribution. Beyond these efficiencies, clerks on teams with stable staffing and clear role differentiation are able to engage in quality improvement activities, such as obtaining and helping interpret team-level clinical performance for quality improvement. Despite such contributions, clerks are often excluded from training opportunities, team meetings, quality improvement projects, and staffing priorities. These omissions result in part from the beliefs of administrative leaders and clinically trained teammates that clerks are interchangeable, unskilled workers without career aspirations. Perhaps the most important limiting factor occurs when administrators mitigate staff shortfalls by assigning clerks to multiple teams, adopting centralized call centers, and intermittently reassigning clerks to other teams or clinics. These strategies affect the entire care system. For example, the combination of high workload and low administrative staffing limits clerks in their ability to tailor services to individual clinicians and develop personal relationships with patients. This organizational climate supports a cascade of role ambiguity, burnout, and inefficiency, where clinical staff may then be asked to perform clerical tasks, thereby limiting the clinicians' ability to work fully within their scope of practice.

\section{OPTIMIZE PCMH BY INVESTING IN CLERKS}

In moving to high-value delivery strategies, health care organizations are challenged to provide care that is both efficient and patient-centered. We believe that an important but underappreciated strategy for health systems to meet these challenges is to better leverage the role of clerks. Drawing upon our prior ethnographic study of PCMH implementation in a large integrated delivery system, ${ }^{1,9,10,13}$ we offer 3 specific suggestions.

First, health systems should ensure that their definition of high-quality primary care encompasses all patient interactions with the health care organization and not simply those between patients and clinically trained staff. Recognizing the opportunities to enhance patient-centered care enveloped within clerical work could help combat patients' perceptions of health care organizations as anonymous institutions.

Second, organizational investment in high-quality care coordination can leverage clerks' contribution to individually tailored, patient-centered care. The benefits afforded by presumed efficiencies in centralized scheduling, for example, should be carefully weighed against potential losses in the quality of tailored care. When clerks answer the telephone or greet patients in 
a waiting room, they have an opportunity to establish rapport with individual patients and initiate a pathway that ensures that patients' preferences and needs are addressed by a health care team with unique roles and capacities.

Third, investment in clerks as health care team members creates short-term costs but potential longterm savings. Costs incurred from a larger clerical workforce and the requisite role-specific training in care coordination, including an emphasis on proactively responding to patient needs and personalizing care delivery, could potentially be offset by reduced turnover, less employee burnout, and fewer inefficiencies arising from unstable teams.

PCMH clerks have unique roles that can be leveraged to better deliver patient-centered primary care. Integration and support of clerks will make it possible for such team-based initiatives as medical homes to optimize their true potential of transforming how patient care is delivered.

To read or post commentaries in response to this article, see it online at http://www.annfammed.org/content/14/4/377.

Key words: patient-centered medical home; primary care; implementation; receptionists; team-based care

Submitted September 8, 2015; submitted, revised, January 22, 2016; accepted February 9, 2016.

Funding support: This work received financial support from the VISN 23 Patient Aligned Care Team Demonstration Laboratory, lowa City VA Health Care System, lowa City, IA, which is funded by the VA Office of Patient Care Services. Additional support comes from the Center for Comprehensive Access \& Delivery Research and Evaluation (CADRE), Department of Veterans Affairs, lowa City VA Health Care System, lowa City, IA (award \# CIN 13-412). Dr Solimeo is a VA HSRED Career Development awardee at the lowa City VA (award \# CDA 13-272).

Disclaimer: The views expressed in this article are those of the authors and do not necessarily reflect the position or policy of the Department of Veterans Affairs or the United States government. None of the funding sources had any role in the design and conduct of the study; collection, management, analysis, and interpretation of the data; and preparation, review, or approval of the manuscript; or decision to submit the manuscript for publication.

Acknowledgments: We wish to acknowledge Sarah S. Ono, Kenda R. Stewart, Monica B. W. Paez, and Michelle Lampman for their contribu- tion to data collection and analysis, and Melissa Fox for technical assistance. We extend our appreciation to the VA Midwest Health Care Network Primary Care and Specialty Medicine Service Line and the VISN 23 PACT Collaborative teams for their participation in our ongoing research.

\section{References}

1. Solimeo SL, Ono SS, Lampman MA, Paez MB, Stewart GL. The empowerment paradox as a central challenge to patient centered medical home implementation in the veteran's health administration. J Interprof Care. 2015;29(1):26-33. 10.3109/13561820.2014. 937480.

2. Rosland A-M, Nelson K, Sun H, et al. The patient-centered medical home in the Veterans Health Administration. Am J Manag Care. 2013;19(7):e263-e272.

3. Jackson GL, Powers BJ, Chatterjee R, et al. Improving patient care. The patient centered medical home. A systematic review. Ann Intern Med. 2013;158(3):169-178.

4. Nutting PA, Crabtree BF, Miller WL, Stewart EE, Stange KC, Jaen CR. Journey to the patient-centered medical home: a qualitative analysis of the experiences of practices in the National Demonstration Project. Ann Fam Med. 2010;8(Suppl 1):S45-S56; S92.

5. Rodriguez HP, Meredith LS, Hamilton AB, Yano EM, Rubenstein LV. Huddle up!: the adoption and use of structured team communication for VA medical home implementation. Health Care Manage Rev. 2015;40(4):286-299.

6. Neuwelt PM, Kearns RA, Browne AJ. The place of receptionists in access to primary care: Challenges in the space between community and consultation. Soc Sci Med. 2015;133:287-295.

7. Hochschild AR. The Managed Heart: Commercialization of Human Feeling. Berkeley, CA: University of California Press; 1983.

8. Arber $S$, Sawyer $L$. The role of the receptionist in general practice: a 'dragon behind the desk'? Soc Sci Med. 1985;20(9):911-921.

9. Solimeo SL, Ono SS, Stewart KR, Lampman M, Rosenthal G, Stewart G. Gatekeepers as care providers: the care work of patient centered medical home clerical staff. Med Anthropol Q. http://onlinelibrary. wiley.com/doi/10.1111/maq.12281/full. Accessed March 28, 2016.

10. True G, Stewart GL, Lampman M, Pelak M, Solimeo SL. Teamwork and delegation in medical homes: primary care staff perspectives in the Veterans Health Administration. J Gen Intern Med. 2014; 29(Suppl 2):S632-S639.

11. Runyan C, Robinson P, Gould DA. Ethical issues facing providers in collaborative primary care settings: do current guidelines suffice to guide the future of team based primary care? Fam Syst Health. 2013;31(1):1-8.

12. Furler JS, Palmer VJ. The ethics of everyday practice in primary medical care: responding to social health inequities. Philos Ethics Humanit Med. 2010;5(5):6.

13. Solimeo SL, Hein M, Paez M, Ono S, Lampman M, Stewart GL. Medical homes require more than an EMR and aligned incentives. Am J Manag Care. 2013;19(2):132-140. 